Original article

\title{
Çocuk Gelişimi Programı Öğrencilerinin Çevresel Tutumlarının Çeşitli Değişkenler Açısından İncelenmesi ${ }^{1}$
}

\section{Investigation of Child Development Program Students' Environmental Attitudes in Terms of Various Variables}

\author{
Hicran Alkan (ㄷ) a, * \& Serap Aktemur Gürler (10 a \\ ${ }^{a}$ Vocational School of Social Sciences, Kafkas University, Kars, Turkey
}

\begin{abstract}
Özet
Çevresel sorunlar, çağımızın en önemli sorunlarındandır. Bunun nedeni, insanların çevreye karşı olumsuz tutum, düşünce ve davranışlardır. Teknolojik, yerel ve küresel önlemler almak, çevre sorunlarını çözmek için yeterli değildir. Çevresel farkındalık ve duyarlıık mutlaka sağlanmalıdır. Bunu gerçekleştirebilmek için, çevre eğitiminin küçük yaşlardan itibaren insanlara kazandırılması gerekmektedir. Verilecek eğitimlerin davranışa dönüştürülmesi için de çaba sarf edilmelidir. Bu eğitimin istenilen düzeyde sonuç verebilmesi için, çevre bilinci gelişmiş öğretmenlerin yetiştirilmesi de önemlidir. Çünkü, öğretmenler öğrencileri için rol model olarak algılanmaktadır. Erken dönemde başlayacak çevre eğitimi sayesinde, çevreye karşı olumlu alışkanlık, tutum ve davranışların daha erken kazanılması mümkün olacaktır. Bu kazanım, olumlu sonuçları da beraberinde getirecektir. Daha yaşanabilir bir dünya için alınabilecek en etkili önlem de bu eğitim kabul edilmelidir. Erken çocukluk döneminde eğitim veren ve davranışların kazanılmasında aktif rol oynayan gruplardan birisi de çocuk gelişimi programı mezunlarıdır. Bu sebeple, çocuk gelişimi öğrencilerinin çevreye duyarlı olarak yetiştirilmesi de ciddi bir kazançtır. Bu çalışmanın amacı; çocuk gelişimi programı öğrencilerinin çevreye ve doğaya karşı olan tutumlarının belirlenmesi ve bu tutumlar üzerinde etkili olan değişkenlerin incelemesidir. Az sayıda araştırma yapılan bu konuda, elde edilen sonuçların başarıya ulaşmak için rehber olacağı düşünülmektedir. Araştırmanın örneklemini, 2018-2019 öğretim yılında Bir devlet üniversitesinin Sosyal Bilimler Meslek Yüksek Okulu Çocuk Gelişimi Programı 1. ve 2. sınıfta öğrenim gören 90 öğrenci oluşturmaktadır. Araştırmada, ön lisans çocuk gelişimi programı öğrencilerinin çevreye yönelik tutumlarını ölçmek amacı ile veri toplama aracı olarak “Çevresel Tutum Ölçeği” kullanılmıştır. Bu ölçek, çevresel problemler için eğitim ge־reksinimi, çevre eğitiminde alan gezilerinin önemi, çevresel kirlilik ve koruma ve çevresel koruᄀma hareketi olmak üzere 4 alt faktör ve toplam 20 maddeden oluşmaktadır. Araştırmada istatistik hesaplamalar, SPSS-18 paket programında yapılmıştır. İstatistiksel hesaplamalarda belirlenen alt faktörlerden elde edilen toplam puanlar ile cinsiyet, yaş, yaşanılan yer ve okul türü gibi değişkenlerin $t$ testi ve ANOVA testleri yapılmıştır. Analiz sonuçları öğrencilerin çevreye karşı tutumlarının belirlenen değişkenler ve faktörlere göre istatistiksel olarak farklılaşmadığını göstermiştir. Bu durum, öğrencilerin çevre eğitimi bakımından benzer bir profil oluşturduğu şeklinde değerlendirilmiştir. Öğrencilerin çevre eğitimi ve bileşenleri konusunda ortalamanın çok üstünde bilgiye sahip oldukları da sonuç olarak belirlenmiştir. Diğer yandan, müfredat kapsamında öğrencilerin aldıkları derslerin yeterli düzeyde olduğu ortaya çıkmıştır.
\end{abstract}

Anahtar Kelimeler: Çevresel tutum, çevre eğitimi, çocuk gelişimi, erken çocukluk dönemi.

\footnotetext{
* Corresponding author:

Hicran Alkan, Vocational School of Social Sciences, Kafkas University, Kars, Turkey.

Email: hicran61alkan@gmail.com

${ }^{1}$ Bu çalışma, 6. Uluslararası Okul Öncesi Eğitimi Kongresinde (IECEC/UOEK-2019) Sözlü Bildiri Olarak Sunulmuştur.
} 


\begin{abstract}
Environmental problems are one of the most important problems of our age. The reason for this is people's negative attitudes, thoughts and behaviors towards the environment. Taking technological, local and global precautions is not enough to solve environmental problems. Environmental awareness and sensitivity must be provided. In order to achieve this, environmental education should be provided to people from an early age. Efforts should also be made to transform the training to be given into behavior. It is also important to train teachers with advanced environmental awareness in order for this education to give desired results, because, teachers are perceived as role models for their students. On account of beginning environmental education at anthe early ages of the child, it would be possible to acquire positive habits, attitudes and behaviors towards the environment earlier. This acquisition would bring positive results with it. The most effective measure that can be taken for a more livable world should be considered this education. One of the groups who teach in early childhood and play an active role in the acquisition of behaviors is child development program graduates. For this reason, it is a serious gain to educate child development students in an environmentally friendly manner. The purpose of this study was to determine the attitudes of students' studying child development program towards the environment and naturein terms of various variables. The results obtained from the current study would be a guide for other studies to be carried out on this subject, which has a limited number of studies. The sample of the study consists of 90 students attending in the 1st and 2nd school year of the Child Development Program of a public university in the 2018-2019 academic year. In the study, "Environmental Attitude Scale" was used as a data collection tool to measure the attitudes of students towards the environment. This scale consists of 20 items in total and 4 sub-factors: the need for education for environmental problems, the importance of field trips in environmental education, environmental pollution and protection and environmental protection movement. Statistical calculations in the study were made using the SPSS-18 package program. T-test and ANOVA tests of total scores obtained from sub-factors determined in statistical calculations and variables such as gender, age, place of residence and school type were performed. The results of the analysis showed that students' attitudes towards the environment did not differ statistically according to the variables and factors. This situation was evaluated as the students created a similar profile in terms of environmental education. As a result, it was determined that the students had high level knowledge about environmental education and its components. On the other hand, it has been revealed that the courses taken by students within the scope of the curriculum are at a sufficient level.
\end{abstract}

Keywords: Environmental attitude, environmental education, child development, earyl childhood term.

Received: 03 September 2020 * Accepted: 01 December 2020 * DOI: https://doi.org/10.29329/jpee.2020.282.5

\title{
GíRiș
}

İnsanların kendi aralarında veya diğer canlılarla etkileşimde bulunduğu, ilişkilerini devam ettirdiği ortama çevre denilmektedir. Başdöndürücü şekilde ilerleyen teknolojinin, tüketimdeki artı̧̧ın ve hızlı kentleşme sürecinin ekosistemi olumsuz yönde etkilememesi için, çevre eğitimi bireylere mutlaka kazandırılmalıdır (Kandır, Yurt ve Cevher-Kalburan, 2012).

Çevre eğitimi esnasında insanların çevre sorunlarının farkına varabilmesi, belirlemiş olduğu bu sorunlara yönelik önlemler alabilmesi ve bu bilinci sürekli hale getirmesi önemli görülmektedir. Çevre eğitimiyle ilgili teorik bilgi vermek yeterli görülmemektedir. Bilginin davranışa dönütürülmesi çabası, çevre eğitiminin esas amacı olmalıdır. Bu amaçla davranışın tekrarlanabilir olması ve bireyin örnek 
alabileceği rol model kavramı gündeme gelmektedir. Bu sebeple eğitim sürecinin ilk yıllarından itibaren çevre farkındalığının başlatılması, öğrenilenin davranışa dönüşmesinde oldukça fazla paya sahiptir.

$\mathrm{Bu}$ açıdan irdelendiğinde erken çocukluk döneminde, çevre eğitiminin davranışa dönüştürülmesinde, okul öncesi öğretmenlerinin ve onlarla birlikte bu süreçte görev alan çocuk gelişimcilerin önemli rol oynayacağı aşikardır. Bu sebeple gerekli çevre bilincinin öncelikle okul öncesi öğretmenlerinde ve çocuk gelişimcilerde olması önemli bir kazanımdır. Bunun sağlanabilmesi için gerek formal eğitimleri aşamasında, gerekse informal eğitim kapsamında çevreye yönelik eğitimin verilmesi de amaca ulaşmak için ihtiyaç olarak belirlenmiştir (Oral, 2004).

Okul öncesi öğretmenleriyle yapılan bir çalışmada, okul öncesi öğretmenlerinin çevreye yönelik algılarının sadece doğayı korumak olduğu ve çevre eğitimi ifadesinden sadece doğayı korumanın anlaşıldığı bildirilmiştir. Oysa, çevre eğitiminin içerisinde doğayı korumak küçük bir kısmı ifade etmektedir (Flogaitis ve Agelidou, 2003; Flogaitis, Daskolia ve Agelidou, 2005).

Çevreye yönelik doğru bilgiye sahip ve bunu davranışa dönüştürebilen öğretmenlerin yetiştirilmesi için, çevreye duyarlı, çevreye yönelik sosyal sorumluluk projelerine katılan ve doğaya karşı saygılı olabilmenin öğretmen adaylarına bilinç olarak kazandırılması gerekmektedir. İlgili literatür incelendiğinde bu alanda yapılan çalışmaların sayısının beklentilerin altında olması dikkati çekmektedir (Kandir vd., 2012).

Çevre konusundaki çalışmaların az olması ve çevre eğitiminin buna karşın ciddi bir öneme sahip olması araştırma konusunun seçiminde en önemli rolü oynamıştır. Bu çalışmanın amacı; erken çocukluk döneminde önemli yere sahip olan okul öncesi ön lisans öğrencilerinin çevreye karşı tutumlarının belirlenmesi, bu tutumlar üzerinde etkili olan değişkenlerin etkisinin saptanmasıdır.

\section{YÖNTEM}

Bu çalışmanın örneklemini; 2018-2019 eğitim-öğretim yılında bir devlet üniversitesinin Sosyal Bilimler Meslek Yüksek Okulu Çocuk Gelişimi Programında öğrenim gören öğrenciler oluşturmaktadır.

Verilerin toplanması amacıyla; 90 öğrenciden oluşan örneklem grubuna, öğrencilerin bazı sosyodemografik özelliklerini içeren bilgilerle birlikte, Fernandez-Manzanal, Rodriguez-Barreiro ve Carrasquer (2007) tarafindan geliştirilmiş ve Türkçeye uyarlanması Yurt ve arkadaşları, (2010) tarafından gerçekleştirilmiş olan "Çevresel Tutum Ölçeği” uygulanmıştır. Sosyo-demografik bölümde öğrencilerin cinsiyet, yaş, aileleriyle birlikte yaşadıkları yerleşim yerleri, mezun oldukları lise türü bilgilerine yer verilmiştir.

Öğrencilerin çevresel tutumlarını belirlemek amacıyla kullanılan Çevresel Tutum Ölçeği (ÇTÖ); dört alt faktörden oluşmaktadır. Ölçek, Çevresel Problemler İçin Eğitim Gereksinimi, Çevre Eğitiminde Alan Gezilerinin Önemi, Çevresel Kirlilik ve Koruma ile Çevresel Koruma Hareketi olmak üzere toplam 
20 maddeden oluşmaktadır. Kesinlikle katılıyorum, Katılıyorum, Kararsızım, Katılmıyorum, Kesinlikle Katılmıyorum ifadelerini içeren 5' li Likert Tipi derecelendirme yapılmıştır. ÇTÖ' inde 8 maddede tersine puanlama yapılmıştır.

$\mathrm{Bu}$ çalışmada demografik özellikler olan cinsiyet, yaş, yaşanılan yerleşim birimi ve mezun olunan okul türüne ile ölçekte belirlenen 4 faktörün toplam puanları arasındaki istatistiksel ilişki irdelenmiştir.

Verilerin istatistiksel analizinde; SPSS-18 paket programından yararlanılmıştır. Araştırmanın verilerinin istatistiksel olarak değerlendirilmesi, ölçeğe ait faktörlerin toplam puanları üzerinden $\mathrm{t}$ testi ve ANOVA testi hesaplamaları ile yapılmıştır.

\section{BULGULAR}

Çalışmada öncelikle araştırmaya katın öğrencilerin sosyo-demografik özellikleri tablo hallinde sunulmuştur (Tablo 1.)

Tablo 1. Araştırmaya katılan öğrencilerin demografik özellikleri

\begin{tabular}{lcc}
\hline Cinsiyet & Frekans & Yüzde \\
\hline Kadın & 72 & 80 \\
\hline Erkek & 18 & 20 \\
\hline Yaş Grubu & Frekans & Yüzde \\
\hline 20 yaş altı & 37 & 41,1 \\
\hline 20 yaşüstü & 53 & 58,9 \\
\hline Yaşanılan Yer & Frekans & Yüzde \\
\hline İl & 28 & 31,1 \\
\hline İlçe & 35 & 38,9 \\
\hline Köy & 27 & 30 \\
\hline Mezun Olunan Okul & Frekans & Yüzde \\
\hline Genel lise & 43 & 47,8 \\
\hline Meslek lisesi & 47 & 52,2 \\
\hline
\end{tabular}

Çalışmaya katılan öğrencilerin 72'sini (\% 80) kadınlar, 18'ini (\% 20) erkekler oluşturmaktadır. Öğrencilerin 37'si (\% 41,1) 20 yaş altında, 53’ü (\% 58,9) 20 yaş üzerindedir. Öğrencilerin yer olarak 28'i (\% 31,1) ilde, 35'i (\% 38,9) ilçede ve 27'si (\% 30) köyde aileleriyle birlikte yaşadıklarını ifade etmişlerdir. Öğrencilerin mezun oldukları okul bazında değerlendirilme yapıldığında 43'ünün (\% 47,8) genel liseden, 47’sinin (\% 52,2) ise meslek lisesinden mezun olduğu görülmektedir.

Araştırmanın istatistiksel verileri elde edilirken belirlenen 4 faktörün toplam puanlarına ilişkin istatistiksel verilerine yer verilmiştir. 


\section{Çevresel Problemler için Eğitim Gereksinimi Faktörüne İlişkin İstatistiksel Hesaplamalar}

$\mathrm{Bu}$ aşamada cinsiyet, yaş, yaşanılan yerleşim birimi ve mezun olunan okul türü demografik veri olarak kullanılmış, "Çevresel Problemler için Eğitim Gereksinimi” faktörüne ilişkin hazırlanmış 5 sorudan elde edilen toplam puanlarla istatistiksel değerlendirmeye tabi tutulmuştur (Tablo 1-4).

Tablo 2. Cinsiyet Değişkenine Bağlı Olarak Çevresel Problemler için Eğitim Gereksinimine Bağlı İstatistik Veriler

\begin{tabular}{lcccccc}
\hline Cinsiyet & $\mathbf{N}$ & $\overline{\mathbf{X}}$ & $\mathbf{S}$ & $\mathbf{s d}$ & $\mathbf{t}$ & $\mathbf{p}$ \\
\hline Kadın & 72 & 16,74 & 3,03 & 88 & 0,774 & 0,441 \\
Erkek & 18 & 17,33 & 2,44 & & & \\
\hline
\end{tabular}

Erkek öğrencilerin çevresel problemler için eğitim gereksinimi ortalama puanlarının $(\overline{\mathrm{X}}=17,33)$ kadın öğrencilerden $(\bar{X}=16,74)$ daha fazla olduğu Tablo 1'de görülmektedir. Kadın ve erkek öğrenciler arasında çevresel problemler için eğitim gereksinimi açısından istatistiksel olarak anlamlı bir farklılık olmadığı görülmektedir $\left(\mathrm{t}_{(88)}=0,77 ; \mathrm{p} \geq 0,05\right)$.

Tablo 3. Yaş Değişkenine Bağlı Olarak Çevresel Problemler için Eğitim Gereksinimine Bağlı İstatistik Veriler

\begin{tabular}{llccccc}
\hline Yaş & $\mathbf{N}$ & $\overline{\mathbf{X}}$ & $\mathbf{S}$ & $\mathbf{s d}$ & $\mathbf{t}$ & $\mathbf{p}$ \\
\hline $0-20$ & 37 & 16,43 & 2,45 & 88 & 1,150 & 0,253 \\
21 ve Üstü & 53 & 17,15 & 3,19 & & & \\
\hline
\end{tabular}

20 yaş üstü öğrencilerin çevresel problemler için eğitim gereksinim puan ortalamalarının $(\overline{\mathrm{X}}=17,15), 20$ yaş altı öğrencilerden $(\overline{\mathrm{X}}=16,43)$ daha fazla olduğu Tablo 2'de görülmektedir. Ancak, öğrencilerin çevresel problemler için eğitim gereksinimlerinin yaş aralığına göre farklılaşmadığı tespit edilmiştir $\left(\mathrm{t}_{(88)}=1,15 ; \mathrm{p} \geq 0,05\right)$.

Tablo 4. Yaşam Yeri Değişkenine Bağlı Olarak Çevresel Problemler için Eğitim Gereksinimine Bağlı İstatistik Veriler

\begin{tabular}{lcccccc}
\hline Varyansın Kaynă̆ı & Kareler Top. & sd & Kareler Ort. & F & p & Anlamlı Fark \\
\hline Gruplar aras1 & 8,700 & 2 & 4,350 & 0,504 & 0,6060 & - \\
Grup içi & 750,422 & 87 & 8,626 & & & \\
Toplam & 759,122 & 89 & & & & \\
\hline
\end{tabular}

Tablo 3 incelendiğinde öğrencilerin çevresel problemler için eğitim gereksinimlerini yerleşim yeri değişkenine bağlı olarak farklılaşmadığı belirlenmiştir $\left(\mathrm{F}_{(2-87)}=0,504 ; \mathrm{p} \geq 0,05\right)$. 
Tablo 5. Okul Türü Değişkenine Bağlı Olarak Çevresel Problemler için Eğitim Gereksinimine Bağlı İstatistik Veriler

\begin{tabular}{lcccccc}
\hline Okul Türü & $\mathbf{N}$ & $\overline{\mathbf{X}}$ & $\mathbf{S}$ & $\mathbf{s d}$ & $\mathbf{t}$ & $\mathbf{p}$ \\
\hline Genel Lise & 43 & 17,37 & 2,55 & 88 & 1,619 & 0,109 \\
Meslek Lisesi & 47 & 16,38 & 3,17 & & & \\
\hline
\end{tabular}

Öğrencilerin çevresel problemler için eğitim gereksinimlerini onların mezun oldukları lise türüne göre farklılaşmamaktadır $\left(\mathrm{t}_{(88)}=1,62 ; \mathrm{p} \geq 0,05\right)$.

\section{Çevre Eğitiminde Alan Gezilerinin Önemi Faktörüne İlişkin İstatistiksel Hesaplamalar}

Geliştirilen ölçekte çevre eğitiminde alan gezilerinin çevre eğitimine katkı sunduğu düşüncesi üzerine farklı bir faktör olarak "alan gezileri" ölçeğe dahil edilmiştir. Bu aşamada cinsiyet, yaş, yaşanılan yerleşim birimi ve mezun olunan okul türü demografik veri olarak kullanılmış "Çevre Eğitiminde Alan Gezilerinin Önemi" faktörüne ilişkin hazırlanmış 5 sorudan elde edilen toplam puanlarla istatistiksel değerlendirmeye tabi tutulmuştur (Tablo 5-8).

Tablo 6. Cinsiyet Değişkenine Bağlı Olarak Çevre Eğitiminde Alan Gezilerinin Önemine Bağlı İstatistik Veriler

\begin{tabular}{lcccccc}
\hline Cinsiyet & $\mathbf{N}$ & $\overline{\mathbf{X}}$ & $\mathbf{S}$ & $\mathbf{s d}$ & $\mathbf{t}$ & $\mathbf{p}$ \\
\hline Kadın & 72 & 19,38 & 3,56 & 88 & 0,564 & 0,574 \\
Erkek & 18 & 19,89 & 2,99 & & & \\
\hline
\end{tabular}

Alan gezilerine kadın ve erkek öğrencilerin bakış açısını ifade eden 5 sorunun ortalama puanları değerlendirildiğinde, kadın öğrencilerin $(\overline{\mathrm{X}}=19,38)$ ve erkek öğrencilerin $(\overline{\mathrm{X}}=19,89)$ bu alandaki ortalama puanlarının oldukça yakın değerler olduğu görülmektedir . Kadın ve erkek öğrenciler arasında çevre eğitiminde alan gezilerinin önemine ilişkin tutumları arasında istatistiksel olarak anlamlı bir farklılık bulunmamıştır $\left(\mathrm{t}_{(88)}=0,56 ; \mathrm{p} \geq 0,05\right)$.

Tablo 7. Yaş Değişkenine Bağlı Olarak Çevre Eğitiminde Alan Gezilerinin Önemine Bağlı İstatistik Veriler

\begin{tabular}{lcccccc}
\hline Yaş & $\mathbf{N}$ & $\overline{\mathbf{X}}$ & $\mathbf{S}$ & $\mathbf{s d}$ & $\mathbf{t}$ & $\mathbf{p}$ \\
\hline $0-20$ & 37 & 19,05 & 3,30 & 88 & 0,976 & 0,332 \\
21 ve Üstü & 53 & 19,77 & 3,53 & & & \\
\hline
\end{tabular}

20 yaş altı $(\overline{\mathrm{X}}=19,05)$ ve 20 yaş üstü $(\overline{\mathrm{X}}=19,77)$ öğrenciler için alan gezilerine dair tutum puanlarının birbirine yakın değerler olduğu Tablo 6'da görülmektedir. Öğrencilerin alan gezilerine ait 
tutumlarının yaş değişkenine bağlı olarak istatistiksel olarak değişmediği/farklılaşmadığı da tespit edilmiştir $\left(\mathrm{t}_{(88)}=0,97 ; \mathrm{p} \geq 0,05\right)$.

Tablo 8. Yaşam Yeri Değişkenine Bağlı Olarak Çevre Eğitiminde Alan Gezilerinin Önemine Bağlı İstatistik Veriler

\begin{tabular}{lcccccc}
\hline Varyansın Kaynă̆ı & Kareler Top. & sd & Kareler Ort. & F & p & Anlamlı Fark \\
\hline Gruplar arası & 29,770 & 2 & 14,885 & 1,264 & 0,288 & - \\
Grup içi & 1024,686 & 87 & 11,778 & & & \\
Toplam & 1054,456 & 89 & & & & \\
\hline
\end{tabular}

Öğrencilerin yerleşim yerleri dikkate alındığında, öğrencilerin çevre eğitiminde alan gezilerine karşı tutumlarının onların yaşamlarını sürdürdükleri yerleşim yerlerine göre istatistiksel olarak değişmediği belirlenmiştir $\left(\mathrm{F}_{(2-87)}=1,26 ; \mathrm{p} \geq 0,05\right)$.

Tablo 9. Okul Türü Değişkenine Bağlı Olarak Çevre Eğitiminde Alan Gezilerinin Önemine Bağlı İstatistik Veriler

\begin{tabular}{lcccccc}
\hline Okul Türü & $\mathbf{N}$ & $\overline{\mathbf{X}}$ & $\mathbf{S}$ & sd & t & $\mathbf{p}$ \\
\hline Genel Lise & 43 & 19,49 & 3,57 & 88 & 0,028 & 0,978 \\
Meslek Lisesi & 47 & 19,46 & 3,35 & & & \\
\hline
\end{tabular}

Genel lise $(\overline{\mathrm{X}}=19,49)$ ve meslek lisesi $(\overline{\mathrm{X}}=19,46)$ mezunu öğrencilerin alan gezilerine dair ortalama tutum puanlarının birbirine çok yakın değerler olduğu Tablo 8'de görülmektedir. Fakat, öğrencilerin çevre eğitiminde alan gezilerine dair tutumlarının onların mezun oldukları okul türüne göre istatistiksel olarak farklılaşmadığ 1 da tespit edilmiştir $\left(\mathrm{t}_{(88)}=0,03 ; \mathrm{p} \geq 0,05\right)$.

\section{Çevresel Kirlilik ve Koruma Faktörüne İlişkin İstatistiksel Hesaplamalar}

Geliştirilen ölçekte çevresel kirliliğin engellenmesine yönelik 5 soru sorulmuş ve bu sorulardan elde edilen toplam puanlar üzerinden istatistiksel hesaplamalar yapılmıştır. Hesaplamanın demografik kısmını teşkil eden cinsiyet, yaş, yaşanılan yerleşim birimi ve mezun olunan okul türü değişkenleri ile "Çevresel kirlilik ve koruma" arasındaki ilişki istatistiksel hesaplamaya tutulmuştur (Tablo 9-12).

Tablo 10. Cinsiyet Değişkenine Bağlı Olarak Çevresel Kirlilik ve Korumaya Bağlı İstatistik Veriler

\begin{tabular}{lcccccc}
\hline Cinsiyet & $\mathbf{N}$ & $\overline{\mathbf{X}}$ & $\mathbf{S}$ & $\mathbf{s d}$ & $\mathbf{t}$ & $\mathbf{p}$ \\
\hline Kadın & 72 & 18,38 & 3,10 & 88 & 0,992 & 0,324 \\
Erkek & 18 & 17,60 & 1,97 & & & \\
\hline
\end{tabular}


Kadın öğrencilerin $(\overline{\mathrm{X}}=18,38)$ erkek öğrencilere $(\overline{\mathrm{X}}=17,60)$ göre çevresel kirlilik ve çevreyi korumaya karşı tutumlarının daha yüksek olduğu ancak Kadın veya erkek öğrenciler arasında çevresel kirlilik ve çevreyi korumaya bakış açıları açısından anlamlı bir farklılık bulunamamıştır .

Tablo 11. Yaş Değişkenine Bağlı Olarak Çevresel Kirlilik ve Korumaya Bağlı İstatistik Veriler

\begin{tabular}{lcccccc}
\hline Yaş & $\mathbf{N}$ & $\overline{\boldsymbol{X}}$ & $\mathbf{S}$ & $\mathbf{s d}$ & $\mathbf{t}$ & $\mathbf{p}$ \\
\hline $0-20$ & 37 & 17,73 & 2,70 & 88 & 1,342 & 0,183 \\
21 ve Üstü & 53 & 18,57 & 3,04 & & & \\
\hline
\end{tabular}

20 yaş üstü öğrencilerin çevresel kirlilik ve çavreyi korumaya karşı tutumlarının 20 yaş altı öğrencilerden daha yüksek olduğu tespit edilmesine rağmen, öğrencilerin çevresel kirlilik ve koruma bilincinin yaş kriterine göre farklılaşmadığ görülmüştür $\left(\mathrm{t}_{(88)}=1,34 ; \mathrm{p} \geq 0,05\right)$.

Tablo 12. Yaşam Yeri Değişkenine Bağlı Olarak Çevresel Kirlilik ve Korumaya Bağgl İstatistik Veriler

\begin{tabular}{lcccccc}
\hline Varyansın Kaynağı & Kareler Top. & sd & Kareler Ort. & F & p & Anlamlı Fark \\
\hline Gruplar arası & 9,298 & 2 & 4,649 & 0,539 & 0,585 & - \\
Grup içi & 750,257 & 87 & 8,624 & & & \\
Toplam & 759,556 & 89 & & & & \\
\hline
\end{tabular}

Öğrencilerin çevresel kirlilik ve çevreyi korumaya bağlı tutumlarının yaşadıkları yerleşim birimlerine göre istatistiksel olarak farklılaşmadığ 1 Tablo 11 'de görülmektedir $\left(F_{(2-87)}=0,54 ; p \geq 0,05\right)$.

Tablo 13. Okul Türü Değişkenine Bağglı Olarak Çevresel Kirlilik ve Korumaya Bağlı İstatistik Veriler

\begin{tabular}{lcccccc}
\hline Okul Türü & $\mathbf{N}$ & $\overline{\mathbf{X}}$ & $\mathbf{S}$ & $\mathbf{s d}$ & $\mathbf{t}$ & $\mathbf{p}$ \\
\hline Genel Lise & 43 & 18,49 & 2,82 & 88 & 0,825 & 0,411 \\
Meslek Lisesi & 47 & 17,98 & 3,01 & & & \\
\hline
\end{tabular}

Genel liseden mezun öğrencilerin çevresel kirlilik ve korumaya bağlı ortalama puan değerlerinin $(\overline{\mathrm{X}}=18,49)$, meslek lisesinden mezun olan öğrencilerden $(\overline{\mathrm{X}}=17,98)$ daha yüksek olmasına rağmen bu farklılık istatistiksel olarak anlamlı değildir. Yani, öğrencilerin çevresel kirlilik ve çevreye karşı koruma tutumları onların mezun oldukları okul türüne göre farklılaşmamaktadır $\left(\mathrm{t}_{(88)}=0,82 ; \mathrm{p} \geq 0,05\right)$.

\section{Çevresel Koruma Hareketi Faktörüne İlişkin İstatistiksel Hesaplamalar}

Öğrencilerin uygulama anlamında çevresel koruma hareketine olan ilgilierini ölçmek için sorulan sorulardan elde edilen toplam puanlar, cinsiyet, yaş, yaşanılan yerleşim birimi ve mezun olunan okul türü değişkenleri ile istatistiksel olarak hesaplamaya tabi tutulmuş, veriler Tablo 13-16'da verilmiştir. 
Tablo 14. Cinsiyet Değişkenine Bağlı Olarak Çevresel Koruma Hareketine Bağgl İstatistik Veriler

\begin{tabular}{lcccccc}
\hline Cinsiyet & $\mathbf{N}$ & $\overline{\mathbf{X}}$ & $\mathbf{S}$ & $\mathbf{s d}$ & $\mathbf{t}$ & $\mathbf{p}$ \\
\hline Kadın & 72 & 17,57 & 2,72 & 88 & 0,059 & 0,953 \\
Erkek & 18 & 17,61 & 2,45 & & & \\
\hline
\end{tabular}

Kadın ve erkek öğrencilerin çevresel koruma teşebbüslerine ilişkin ortalama tutum puanlarının birbirine çok yakın olduğu Tablo 13'de görülmektedir. Öte yandan, kadın ve erkek öğrenciler arasında çevresel koruma teşebbüsleri açısından istatistiksel olarak anlamlı bir faklılık bulunmamıştır $\left(\mathrm{t}_{(88)}=0,06\right.$; $\mathrm{p} \geq 0,05$ ).

Tablo 15. Yaş Değişkenine Bağlı Olarak Çevresel Koruma Hareketine Bağlı İstatistik Veriler

\begin{tabular}{lcccccc}
\hline Yaş & $\mathbf{N}$ & $\overline{\mathbf{X}}$ & $\mathbf{S}$ & $\mathbf{s d}$ & $\mathbf{t}$ & $\mathbf{p}$ \\
\hline $0-20$ & 37 & 16,95 & 2,65 & 88 & 1,913 & 0,059 \\
21 ve Üstü & 53 & 18,01 & 2,60 & & & \\
\hline
\end{tabular}

20 yaş üzeri öğrencilerin $(\overline{\mathrm{X}}=18,01), 20$ yaşın altında olanlara $(\overline{\mathrm{X}}=16,95)$, göre çevresel koruma hareketlerine karşı daha bilinçliolduğu Tablo 14'den görülmektedir. Ancak, öğrencilerin çevresel koruma hareketlerine karşı tutumlarının onların yaş aralıklarına göre istatistiksel olarak farklılaşmadığı belirlenmiştir $\left(\mathrm{t}_{(88)}=1,91 ; \mathrm{p} \geq 0,05\right)$.

Tablo 16. Yaşam Yeri Değişkenine Bağlı Olarak Çevresel Koruma Hareketine Bağgl İstatistik Veriler

\begin{tabular}{lcccccc}
\hline Varyansın Kaynağı & Kareler Top. & sd & Kareler Ort. & F & p & Anlamlı Fark \\
\hline Gruplar arası & 15,963 & 2 & 7,981 & 1,135 & 0,326 & - \\
Grup içi & 611,993 & 87 & 7,034 & & & \\
Toplam & 627,956 & 89 & & & & \\
\hline
\end{tabular}

Öğrencilerin çevresel koruma hareketlerine karşı tutumları onların yaşadıkları yerleşim yerlerine göre istatistiksel olarak farklılaşmadığı belirlenmiştir $\left(F_{(2-87)}=1,13 ; p \geq 0,05\right)$.

Tablo 17. Okul Türü Değişkenine Bağl1 Olarak Çevresel Koruma Hareketine Bağl1 İstatistik Veriler

\begin{tabular}{lcccccc}
\hline Okul türü & $\mathbf{N}$ & $\overline{\mathbf{X}}$ & $\mathbf{S}$ & $\mathbf{s d}$ & $\mathbf{t}$ & $\mathbf{p}$ \\
\hline Genel Lise & 43 & 17,53 & 2,91 & 88 & 0,146 & 0,884 \\
Meslek Lisesi & 47 & 17,61 & 2,44 & & & \\
\hline
\end{tabular}

Öğrencilerin çevresel koruma hareketine bağlı tutumlarının onların mezun oldukları okul türüne bağlı olarak farklılaşmadığı tespit edilmiştir $\left(\mathrm{t}_{(88)}=0,14 ; \mathrm{p} \geq 0,05\right)$. 


\section{TARTIŞMA, SONUÇ VE ÖNERILER}

Elde edilen veriler ve istatistik değerlendirmeler sonucunda hiçbir değişken ve faktör arasında anlamlı bir farklılı̆̆ın bulunmaması, araştırmanın sonucu bakımından ciddi bir sonuç elde edilememiş gibi görülebilir. Oysa bu sonuç, örneklem grubuna bakıldığında çevresel tutum özelliklerinin çok benzer olduğu şeklinde yorumlanmalıdır. Zira, Mikami, Takeshita, Nakada ve Kawabata (1995); Evans, Gill ve Marchant (1996); Chan (1999); Pant (2005); Vrasidas ve diğerleri (2007), Kostova ve Atasoy (2008) yapmış oldukları çalışmalarda her yaştan, farklı statülerden ve değişik bölgelerden geniş gruplarla çalışmış olup, öğretmen adaylarının ve okul öncesi öğretmenlerinin çevresel tutum durumlarında istatistiksel olarak anlamlı farklılık elde edememiştir. Bu geniş çalışmalar sonuç açısından yaptığımız araştırma ile benzerlik göstermektedir.

Diğer yandan elde edilen toplam puan değerlerine bakıldığında puanlar arasında farklılıkların varlığı görülmektedir. Bu farklılığın istatistiksel olarak anlamlı bulunmamış olması standart değerlerin elde edildiği şeklinde yorumlanmamalıdır. Çevre eğitimi bakımından benzer bir öğrenci profilinin olduğu şeklinde değerlendirme yapmak daha doğru bir yaklaşım olacaktır.

Üzerinde çalışma yapılan faktörden elde edilen ortalama puan değerlerine bakıldığında, öğrencilerin çevre eğitimi ve bileşenleri konusunda ortalamanın çok üstünde bilgiye sahip oldukları ve müfredat kapsamında aldıkları derslerin yeterli düzeyde olduğu ortaya çıkmaktadır.

Öğrencilerin çevresel farkındalıklarını arttırmak için çocuk gelişimi programında öğrenim gören öğrencilerin sosyal sorumluluk projelerine dahil edilmeleri, bu alanda gezi ve gözlem programlarına yöneltilmeleri ile disiplinler arası işbirliği yapmaları farkındalı̆̆ı artıracak bir çaba olacaktır.

\section{KAYNAKLAR}

Chan, K. K. W. (1999). Mass media and environmental knowledge of secondary school students in Hong Kong. The Environmentalis, 19(2), 85-97.

Evans, S. M., Gill, M. E., \& Marchant, J. (1996). Schoolchildren as educators: The indirect influence of environmental education in schools onparents' attitudes towards the environment. Journal of Biological Education, 30(4), 243-248.

Flogaitis, E., \& Agelidou, E. (2003). Kindergarten teachers'conceptions about nature and the environment. Environmental Education Research, 9(4), 125-136.

Flogaitis, E., Daskolia, M., \& Agelidou, E. (2005). Kindergarten teachers' conceptions of environmental education. Early Childhood Education Journal, 33(3), 125-136.

Kandır, A., Yurt, Ö., \& Cevher-Kalburan, N. (2012). Okul Öncesi Öğretmenleri ile Öğretmen Adaylarının Çevresel Tutumları Yönünden Karşılaştırılması. Kuram ve Uygulamada Eğitim Bilimleri. Educational Sciences: Theory \& Practice, 12(1), 317-327. 
Kostova, Z., \& Atasoy, E. (2008). Çevre eğitiminde başarılı öğrenme yöntemleri. Eğitimde Kuram ve Uygulama, 4 (1), 49-78.

Mikami, S., Takeshita, T., Nakada, N., \& Kawabata, M. (1995). The media coverage and public awareness of environmental issues in Japan. International Communication Gazette, 54(3), 209-226.

Oral, B. (2004). Eğitim Fakültesi Öğrencilerinin Öğretmenlik Mesleğine İlişkin Tutumları. Eğitim Araştırmaları Dergisi, 15, 88-98.

Pant, H. (2005). Attitude of distance learners towards multimedia approach to instruction. Asian Association of Open Universities Journal, 1(1), 65-72.

Vrasidas, C., Zembylas, M., Evagorou, M, Avraamidou, L., \& Aravi, C. (2007). ICT As a tool for environmental education, peace and reconciliation. Educational Media International, 44(2), 129-140.

Yurt, Ö., Cevher-Kalburan, N., \& Kandır, A. (2010). Investigation of the environmental attitudes of the early childhood teacher candidates. Procedia-Social and Behavioural Sciences, 2 (2), 4977-4984. 